\title{
Abbreviations of Archival Sources
}

\begin{tabular}{|c|c|}
\hline ASF & Florence, Archivio di Stato \\
\hline $\mathrm{AD}$ & Acquisti e doni \\
\hline $\mathrm{CP}$ & Consulte e pratiche \\
\hline CPGNR & Capitani di parte guelfa. Numeri rossi \\
\hline CRSGF & $\begin{array}{l}\text { Corporazioni religiose soppresse dal Governo } \\
\text { francese }\end{array}$ \\
\hline CRSPL & Corporazioni religiose soppresse da Pietro Leopoldo \\
\hline CS & Carte strozziane \\
\hline Dipl. & Diplomatico \\
\hline LC & Signoria. Carteggi. Legazioni e commissarie \\
\hline MAP & Archivio Mediceo avanti il Principato \\
\hline MC & Monte comune \\
\hline Misc. rep. & Miscellanea repubblicana \\
\hline Miss. I canc. & Signoria. Carteggi. Missive. Prima Cancelleria \\
\hline NA & Notarile antecosimiano \\
\hline OGBR & Otto di guardia e balia. Periodo repubblicano \\
\hline $\mathrm{PP}$ & Provvisioni. Protocolli \\
\hline PR & Provvisioni. Registri \\
\hline RAP & Riformagioni. Atti pubblici \\
\hline SC Delib. ord. & $\begin{array}{l}\text { Signoria. Collegi. Deliberazioni fatte in forza di } \\
\text { ordinaria autorità }\end{array}$ \\
\hline SC Delib. spec. & $\begin{array}{l}\text { Signoria. Collegi. Deliberazioni fatte in forza di } \\
\text { speciale autorità }\end{array}$ \\
\hline ASM & Milan, Archivio di Stato \\
\hline Pot. est. & Potenze estere \\
\hline ASV & Vatican City, Archivio Segreto Vaticano \\
\hline RA & Registra Avenionensia \\
\hline RV & Registra Vaticana \\
\hline ASVe & Venice, Archivio di Stato \\
\hline $\mathrm{CI}$ & Cancelleria inferiore \\
\hline
\end{tabular}



GP Giudici di petizion
SG Sentenze a giustizia
Test. Testamenti

BAM

Milan, Biblioteca Ambrosiana

BAV

Vat. lat.

Vatican City, Biblioteca Apostolica Vaticana

BLF

Fondo Vaticano latino

Ashb.

Florence, Biblioteca Medicea Laurenziana

ASL

Manoscritti Ashburnham

Conv. soppr.

BNF

Archivio di San Lorenzo

F.P.

Conventi soppressi

Magl.

Florence, Biblioteca Nazionale Centrale

Fondo principale

Pal.

Fondo Magliabechiano

Strozz.

Fondo Palatino

BRF

Fondo Strozziano

Ricc.

Florence, Biblioteca Riccardiana

Fondo Riccardiano

BSS, AC

Borgo San Sepolcro, Archivio comunale

Paris, BN

Ms. Ital.

Paris, Bibliothèque Nationale

Manuscrits Italiens 